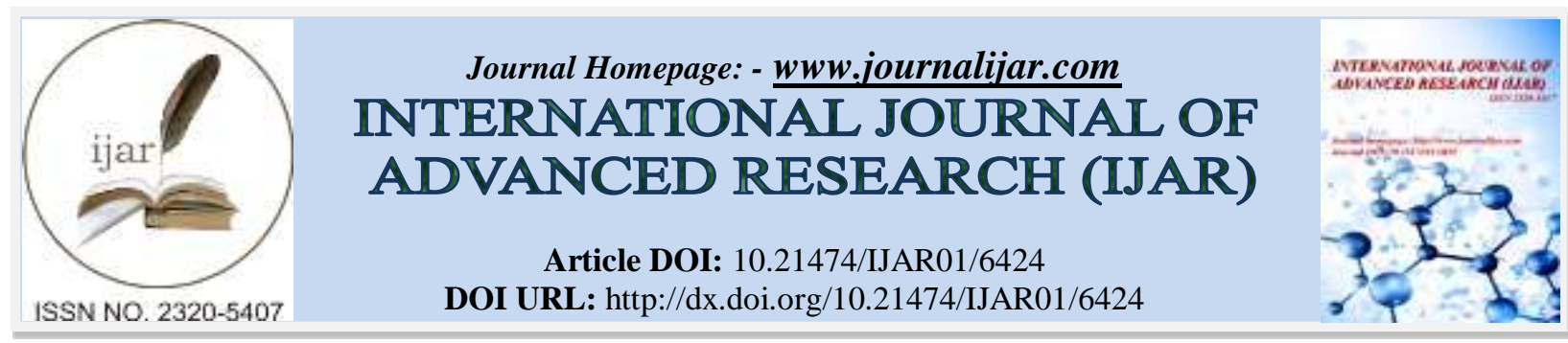

RESEARCH ARTICLE

\title{
THE ASSESSMENT OF FINANCIAL SUSTAINABILITY OF HEALTH INSURANCE IN AFRICA: A CASE STUDY OF GHANA'S NATIONAL HEALTH INSURANCE SCHEME.
}

Dennis Asante ${ }^{1}$, Kingsford Kissi Mireku ${ }^{2}$, Isaac Edem Djimesah ${ }^{3}$ and Kenneth Wilson Adjei Budu ${ }^{4}$.

1. School of Management and Economics, University of Electronic Science and Technology of China.

2. School of Information and Software Engineering, UESTC, Chengdu, China.

3. School of Finance and Economics, Jiangsu University, Zhenjiang, China.

4. School of Management and Economics, University of Electronic Science and Technology of China.

\section{Manuscript Info}

(..........................

Manuscript History

Received: 03 December 2017

Final Accepted: 05 January 2018

Published: February 2018

Key words:-

Funding adequacy, financial sustainability, health insurance, insurance scheme, Ghana.

\section{Abstract}

Most nations prioritize the provision of affordable healthcare for their residence via health insurance. However, a substantial financial base recognized widely as a prerequisite for the provision of an efficient health care delivery system. This study aims to assess the financial sustainability of health insurance in Africa using Ghana's National Health Insurance Scheme as a case study. The study examined the funding regime, the growth rate of claims, premium payments, and income and expenditure trends of the scheme from 2008 to 2014 with GNHIS's annual reports used as data collection. The study adopted the "four pillars of financial sustainability" to test the impact of claims and investment on return on asset (ROA) of the scheme, using ROA as a proxy for financial sustainability. The results show a statistically significant negative relationship between ROA and Investment $(\beta=-$ $0.1700964, \mathrm{p}=0.049$ ) implying that a unit point increase (or decrease) in the scheme's investments will cause the scheme's ROA to decrease (or increase) by approximately 0.17 units points. Likewise, claims payment showing a statistically significant adverse impact on ROA $(\beta=-0.2278903, p=0.036)$. Unit growth in claims payment reduces the scheme's sustainability by 0.22 units. Overall, investment and claims jointly influence 86.39 percent of the variation in the scheme's financial viability. This study's findings give credence to the need for coherent policies directed to salvage GNHIS from imminent collapse. The study concludes that GNHIS needs immediate policy diagnostics and operational restructuring to avert the current financial challenges bedeviling the scheme.

Copy Right, IJAR, 2018,. All rights reserved.

\section{Introduction:-}

Health is the absence of infirmities and physical diseases. World Health Organization (WHO) defines health as "a state of complete mental, physical and social well-being of people and not just merely absence of disease or infirmity." Health issues are paramount to every nation irrespective of the level of development. The health of the population of any country determines the country's capacity to produce and benefit from schooling and its ability to derive income from employment ${ }^{[1]}$. A survey conducted by a joint $\mathrm{NGO}$ on health insurance implementation in 
Africa indicated that an average of 100 million people is pushed into poverty yearly as a result of health care need ${ }^{[2]}$. Appiah-Denkyira and Preker (2007) observed that the primary challenge facing Africa in guaranteeing fundamental health care to citizens bothers on finance systems ${ }^{[3]}$.

Health insurance may be organized either as a private sector purchased insurance by individuals hedging against the risks and the adverse effect of ill-health or as social health insurance. Health insurance schemes in Africa are increasingly recognized as a potential panacea for health care financing quagmire. These systems are believed to have the potential to enhance health facility utilization and as well protect people against high health care expenses. Additionally, health insurance schemes have the innate potential to address issues of equity ${ }^{[4]}$. Financing health care through general taxation or the implementation of social health insurance policy is recognized as practical methods to achieve universal coverage with sufficient financial security for all against healthcare burden ${ }^{[5]}$. A substantial fiscal foundation recognized widely serves as a prerequisite for an efficient health care delivery system. Available literature shows that Governments in sub-Saharan Africa face severe financial constraints in their effort to provide primary health care needs to their people (Abekah-Nkrumah et al. 2009) ${ }^{[6]}$.

According to (WHO 2010) report, Health insurance in Africa is still having challenges with Ghana facing sustainability concerns concerning the National Health Insurance Scheme (NHIS) ${ }^{[4]}$. Some factors threaten the sustainability of Ghana's NHIS. These include provider's incentives to over-prescribe; very generous benefits package to cover $95 \%$ disease burden; Ineffective referral system due to patients inability to seek care from higher level facilities; and under-developed monitoring systems within the NHIS. Moreover, the Ghana scheme has also reported deficit on its balance sheet since the year 2009 further worsening the plight and sustainability of it.

A robust fiscal base is a precondition for an efficient and sustainable healthcare delivery system. Earlier studies have already pointed out that most Governments in sub-Saharan Africa face financial constraints in the provision of primary healthcare services to their citizens ${ }^{[6]}$. Remaining financially sustainable does not only imply having consistent and reliable sources of funding, but the adequacy of the funds to support claim reimbursements and other mandatory expenditure on the Scheme ${ }^{[7]}$.

In the case of Ghana, the scheme managers, as well as other authors, have queried the financial sustainability of the NHIS (Abekah-Nkrumah et al. 2009) ${ }^{[6]}$. The Ghana NHIS is reliant on two significant sources of fundings namely the NHIS levy and Social Security and National Insurance Trust (SSNIT). Contributions from the NHIS levy and SSNIT account for over 90 percent $(90 \%)$ of funding for the scheme. Whereas enrollment onto the system has soared since the year 2009, the scheme has consistently reported net operating deficits during the same period casting doubts on the financial health of it (NHIA Reports, 2009-2015, Jehu-Appiah, 2010) ${ }^{[8-14]}$. According to Leon (2001), an organization is extremely vulnerable to financial shocks if a significant portion of its budget is dependent on a few sources ${ }^{[15]}$.

The second pillar of financial sustainability as promulgated by Leon $(2001)^{[15]}$ requires that organizations do not only generate funds internally but also diversify their funding sources to remain financially sustainable. Managers of the Ghana NHIS scheme have often grumbled about inadequate revenue to defray increasing insurance claims. Also, insurance claims inflation by service providers is being reported. The continuous downturn in the financial fortunes of the Ghana NHIS has been a matter of grave concern to both patrons and managers alike. The introduction of capitation payment system in certain parts of the country is an attempt to revive the scheme. This measure has yet to reverse the financial ruins of the project. Many of the populace has even predicted the imminent collapse of the scheme if appropriate measures are not rolled out to ensure its sustainability. As yet, the few studies on the financial jurisprudence of the Ghana NHIS have focused on district-level schemes and not on the national level (Kofi Owusu Yeboah and Moses Kormedoda, 2014) ${ }^{[16]}$.

A study on Sustainable Health Care Financing in Ghana through National Health Insurance revealed that whiles there are success stories to tell since the introduction of NHIS, persistently increasing claims and other implementation challenges have endangered the sustainability of the scheme. While this may be due to the increasing numbers of active members, moral hazards from both provider and subscriber ends may not be ruled out (Owusu-Sekyere et al., 2014).

This study's objective is to assess the financial sustainability of the health insurance in Africa using Ghana's national health insurance scheme. The study, therefore, aims to examine the funding sources of it, the growth rate of 
utilization and claims payment trends, the growth rate of active membership, claims and premium payment trends in the scheme. It further analyzes the income and expenditure trends, and to examine the impact of claims and investment on the financial sustainability of the scheme. This study sheds more light on the funding gaps in African's insurance schemes and makes future projections of the scheme implementers, serving as a policy guide to administrators and policymakers.

\section{Methodology:-}

This study uses descriptive qualitative approach, with the design of rapid assessment procedure, which is a way to improve and understand the problems encountered in implementing health programs by using a qualitative method. Data validity check is done using triangulation technique, i.e., comparing the data obtained from one source with other data from other sources in a different period, or comparing the data received from one source using different methods

This study adopts mixed method approach (both qualitative and quantitative) for data collection and analysis. The technique focuses on meaning and also measures quantifiable phenomena in which the first part of the investigation is an extensive review of the literature (qualitative approach) in scholarly research articles, books and reports from World Bank, UNDP, WHO and national government policy and reports on the Ghana national health insurance scheme.

The second part of the analysis (quantitative approach) uses financial tools and regression analysis to assess the impact of claims (major expense on the scheme), investment (main diversified income source) and microeconomic indicators (external factors) on the financial sustainability of the Ghana National Health Insurance Scheme (GNHIS).

\section{Qualitative method:-}

Kruger and Mitchell (2005) ${ }^{[17]}$ argue that qualitative research focuses on processes and meaning rather than an evaluation of terms that relies on quantity, amount, intensity or frequency. With this approach, the study uses trend analysis to compares schemes data over time to identify any consistent results or trends. It will help the scheme to develop an effective strategy to respond to these trends in line with the scheme's goals and predicting the future direction.

This study then employed document study for both data gathering source and review of relevant literature which are all secondary data. Secondary data are information collected by individuals or agencies and institutions other than the researcher him- or herself ${ }^{[17]}$. Our secondary data source has been stated in our second paragraph under methodology within seven years period (i.e., 2008 to 2014). In particular, the financial data on the scheme extracted from the annual financial reports on the GNHIS ${ }^{[8]-[13]}$ also from 2008 to 2014. Data on CPI (inflation) and GDP growth rate were from World Bank.

\section{Quantitative method:-}

Quantitative analysis refers to economic, business or financial analysis that uses mathematical measurements and calculations, statistical modeling and research with the aim to understand or predict behavior or events. The study uses Ordinary Least Squares (OLS) regression to estimate the impact of the independent variables on the dependent variables. The OLS is preferred because, according to Gauss-Markov theorem, it is the Best Linear Unbiased Estimator (BLUE); consistent and efficient. Moreover, in the midst of unbiased linear estimators, OLS has the minimum variance. However, before the OLS estimation, the Augmented Dickey-Fuller (ADF) test was administered on the variables to check for stationarity considering the data being a time series data[18] [19]. Besides, the $\mathrm{F}$ test was used to test for the overall effect of independent variables on the dependent variable. In all the experiments, the p-value approach, as well as the critical value approach, was used in concluding. A 5\% level of significance used as a measurement in the study.

\section{Variables and measurement definition}

An organization that is sustainable in the short term but not, in the long run, may have an adequate supply of cash but microeconomic factors such as inflation may deplete the value of the money with time ${ }^{[20]}$. Applying accounting principles of financial sustainability to nonprofits, gross earnings (total revenue) less total costs (Direct + overhead costs) indicates the organizations' sustainability over time. Among nonprofit organizations, a positive output is a surplus whiles a negative output is a deficit. In the corporate world, surplus and deficit refer to profits and losses 
respectively. Therefore, this study used return on assets to measure the financial sustainability of the GNHIS. Return on assets (ROA) is an indicator of how profitable a company is relative to its total assets. ROA provides a concept as to how efficient management is at using its assets to generate earnings. ROA is computed by dividing a company's yearly earnings by its total assets and displayed as a percentage. Even though the GNHIS is a nonprofit organization, it is expected to operate a "0" balance sheet or a surplus as a hedge for short-term and future financial shocks. ROA thus is the dependent variable in the analysis.

Claims by service providers on the GNHIS remain the highest expenditure on the scheme's income and expenditure budget. Tall claims without a corresponding increase in revenues have a negative impact on the net income (surplus or deficit) on the scheme. This phenomenon may invariably impact on the sustainability of it. Service providers test claims as an independent variable in the regression analysis. Over 90 percent of funding for the GNHIS is by SSNIT contributions and the NHIS levy. Over-reliance on these two funders puts the scheme at risk since these are statutory funding sources, its sustainability is dependent on the political will and priority of the national government. The return on the scheme's investment is the only diversified external funding source and thus is key to ensuring especially the long-term sustainability of the system. The scheme's investment tests as a predictor of the financial viability of the GNHIS. Table 1 provides a summary of the variables, their corresponding proxies, and definitions.

Table 1:- variables, their measurement, and Notations

\begin{tabular}{|l|l|l|l|}
\hline Variable & Variable type & Notation & Measurement \\
\hline Return on Assets & Dependent & ROA & (Net Income/Total Assets)\% \\
\hline Claims & Independent & $\operatorname{lnC}$ & Log of claims \\
\hline Investment & Independent & $\operatorname{lnINV}$ & Log of investment \\
\hline
\end{tabular}

\section{Models Specification:-}

The general model using the variables above is:

$\mathrm{ROA}_{\mathrm{t}}=\mathrm{f}\left(\mathrm{C}_{\mathrm{t}}, \mathrm{INV}_{\mathrm{t}}, \varepsilon_{\mathrm{t}}\right)$ Equation (1)

Where:

$\mathrm{C}_{\mathrm{t}},=$ Claims payment to service providers (in GHC million)

$\mathrm{INV}_{\mathrm{t}}$, = Returns on investment by the scheme (in GHC million)

$\varepsilon_{\mathrm{t}}=$ The stochastic term representing other relevant variables excluded in the equation

$\mathrm{t}=$ Time (from 2008 to 2014)

The unit of measurement is unprecedented for each variable in the model. The natural log of each variable was used to normalize the differences in the elements of each variable applied. Taking the natural log of variables links the gap between and among variables and make them moderately uniform and to reduce the feasibility of Heteroskedasticity ${ }^{[21]}$.

The specific model thus becomes:

$\mathrm{ROA}_{\mathrm{t}}=\beta_{0}+\beta_{1} \ln C_{\mathrm{t}}+\beta_{2} \operatorname{lnINV} \mathrm{t}_{\mathrm{t}}+\varepsilon_{\mathrm{t}} \ldots$

Equation (2)

Where

$\beta_{0}$ measures the output level(surplus or deficit) holding all the independent variables constant;

$\beta_{1}$ and $\beta_{2}$ are standardized coefficients that measure the strength of the respective distinctive effect of the independent variables in the model on the dependent variable

The Four Pillars of Financial Sustainability:-

Patricia León's analysis of the four pillars of financial sustainability offers a basis for this research. Leon asserted that financial viability based on the four components: financial and strategic planning, income diversification, sound administration and finance and own income generation (Leon 2001, p.15-17) ${ }^{[15]}$.

\section{Financial and Strategic Planning:-}

Strategic planning according to Leon is the mechanism to help clarify an organization's mission and objectives as well as prioritize the efforts needed to achieve them. She argues that effective planning is the essential prerequisite for nonprofit agencies to a position in accessing funds better. To implement organizational strategies rest on the availability of financial resources, hence financial planning. The author describes financial planning as projected expenditures and the organization's potential to generate the income to cover those expenses ${ }^{[15]}$. The study makes a distinction between budget and financial plan by further describing the latter as a document that determines whether an organization is going to have enough resources in the medium term to meet the strategic objectives. 


\section{Income Diversification:-}

The second pillar of financial sustainability discussed in Leon's work (2001) explains as diverse sources of funds for a scheme or project including internal generation and external donation or grants. The author asserts that $60 \%$ or more of an organization's income must come from five different sources. The study argues that irrespective of the number of sources of funds available to an association, it remains vulnerable if a significant proportion of its budget depends on only one of the sources. Any shock or financial stress on this funding stream negatively affect the operations of the dependent organization ${ }^{[15]}$.

\section{Sound Administration and Finance:-}

Leon (2001) contends that to attain financial sustainability, effective and efficient management of resources is as important as knowing how to generate income. The author's argument on financial administration focuses on series of institutional policies that help to ensure transparency in fiscal management. She further asserts that sound financial management allows organizations to generate income through executive of available assets. The study recommends that the accounting departments must give priority to; grant reports, trust fund, income generation through business activities, financial statements to donors and project audits ${ }^{[15]}$.

\section{Own Income Generation:-}

The fourth pillar according to Leon's argument is the organizations capacity to generate income aside donations and grants from government and donor foundations. This owning of income should take the form of investing in trust funds, fundraising activities, the sale of goods and services, establishing businesses related to an organization's mission, etc. (Leon, 2001) ${ }^{[15]}$.

\section{Data trend analysis and results of NHIS in Ghana:-}

As stated earlier on, the primary funding sources of the NHIS in Ghana is in Table 2 below.

Table 2:- Funding sources of GNHIS. Source: NHIA (2010)

\begin{tabular}{|l|l|l|l|l|l|}
\hline Year & NHIS levy & SSNIT & Investment & Premium & Other \\
\hline 2008 & 277.71 & 55.80 & 36.15 & 16.54 & 11.58 \\
\hline 2009 & 329.46 & 65.00 & 75.64 & 15.83 & 16.91 \\
\hline 2010 & 314.84 & 87.01 & 58.80 & 0.00 & 0.31 \\
\hline 2011 & 449.97 & 107.61 & 32.00 & 27.64 & 0.57 \\
\hline 2012 & 573.36 & 141.76 & 29.07 & 28.56 & 1.75 \\
\hline 2013 & 650.20 & 180.49 & 42.25 & 30.58 & 0.78 \\
\hline 2014 & 738 & 204.00 & 16.00 & 34.00 & 8.00 \\
\hline
\end{tabular}

The GNHIS funded by government taxation mainly (NHIS levy and SSNIT) and premium payments as indicated in (Table 2). This observed trend has been consistent over the years as can be seen from (Fig 1). The second major contributor to the scheme's finance is SSNIT contributor's $2.5 \%$ monthly income deductions. NHIL and SSNIT together contribute over $90 \%$ of the NHIS's total income. Premium, investment and other unclassified sources of revenue to the scheme constitute less than $10 \%$ of the total accumulated under the system (see Figure 1).

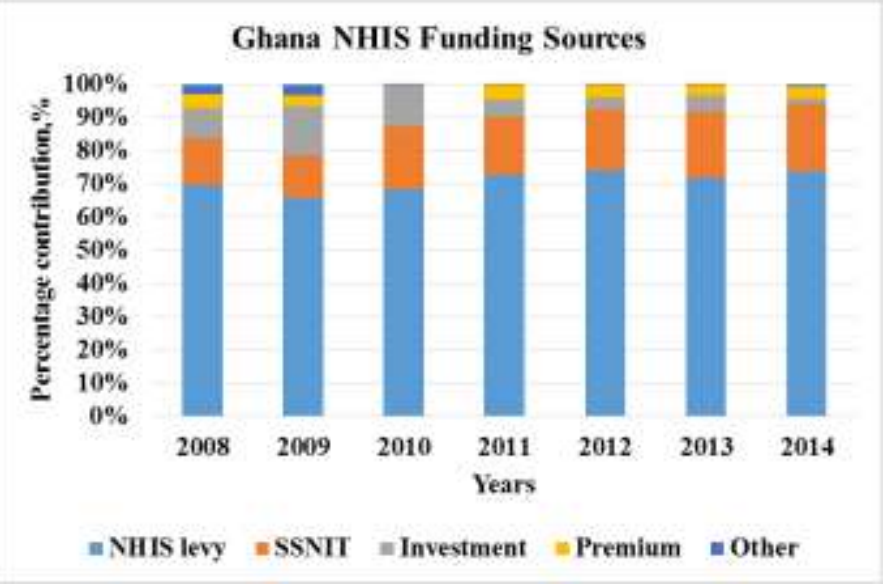

Figure 1:- Funding sources for GNHIS. 


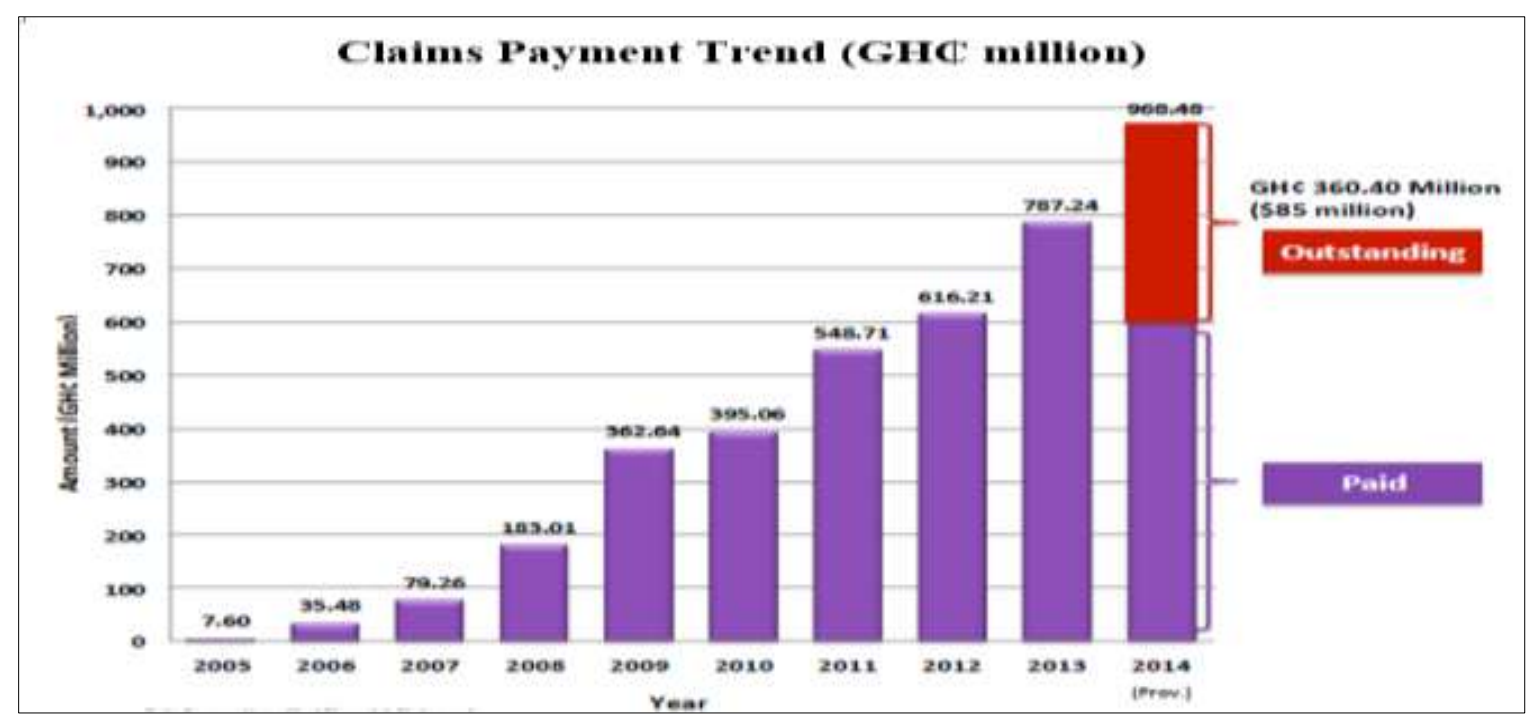

Figure 2:- Claims payment trend. Source: Adapted from Jehu-Appiah (2015)

A return on Investment (ROI) is the third primary funding source for the scheme. However, the growth rate of investment returns has assumed a downward trend over the years. A 38.5\% growth on investment returns was recorded from 2008 to 2010 and sharply decreased from GHC 42.25 million to GHC 16.00 million from 2013 to 2014 which translates into 164\% reduction. From 2009 to 2014, investment returns have recorded 373\% decrease, tumbling from GHC 75.64 million to GHC 16.00 million (Table 2 above).

Looking at the scheme's stream of funding, the only primary diversified source of income is ROI. Unfortunately, ROI's rapid decline leaves the NHIS to impending financial threat in the future. Leon opines that for the organization to immunize itself from financial quagmire and remain sustainable to deliver its mandate, at least 60 percent of its funding should come from more than four sources ${ }^{[15]}$. Additionally, one of the major propositions of Social Health Insurance (SHI) theory is pooling of diverse resources against anticipated risk. In the case of Ghana's NHIS, the funding skewed to government taxation narrowly. In line with Leon's argument together with the consistent decline of ROI, this study finds the GNHIS's over-reliance on government tax allocations (i.e., limited funding and less diversified sources) as detrimental to the long-term financial sustainability of the scheme. Thus, any change in government and or a change in government policy on public expenditure can quickly affect the scheme.

\section{Claims Payment trend:-}

There are emerging issues that seek to threaten the financial sustainability of the national health insurance scheme, but our research focused on lack of funds that led to the persistent indebtedness to service providers by the NHIA. The intensity and impact of this pose a fundamental challenge to the scheme and blaming it on escalating claims payment by the NHIA. The findings of the research have proven that claims payment is the primary cost driver of the scheme. It is shown in figure 2 by Jehu-Appiah $(2015)^{[14]}$

The study results show that currently, NHIS expenditures exceed revenues. There have often been outstanding arrears of claims carried into the ensuing year. The study further indicated how fast claims payments are increasing over the years. From 2008 to 2014, claims have more than quadrupled. This trend of steady increment of claims has resulted in rapid financial dissipation under the scheme putting the NHI into further financial woes.

\section{Growth Rate of Utilization and Claims trend:-}

While in nominal values it is observable that service utilization under the Ghana NHIS has been increasing over the years, the actual growth rate of usage has been wavering. Both in-patient and out-patient utilizations growth rate have been up and down along the years and finally assumed some level of stability from 2012 to 2014 (see Figure 3). In a standard insurance scheme, if utilization tumbles then a resultant decline of claims is recorded. On the contrary, when utilization falls under the GNHIS, the correspondent decrease in claims are not felt. It is due to the inefficiencies such as moral hazard on the part of both supply and demand side of the scheme. Akpalu's study on ten 
years of Financial Access to Quality Healthcare discussed that substantial corruption and moral hazard in the form of claims padding, multiple visits to accredited facilities and among others are significant contributions to the unrestrained growth of cost under NHIS of Ghana (Akpalu, 2013) ${ }^{[22]}$. It is consistent with the conclusion stated.

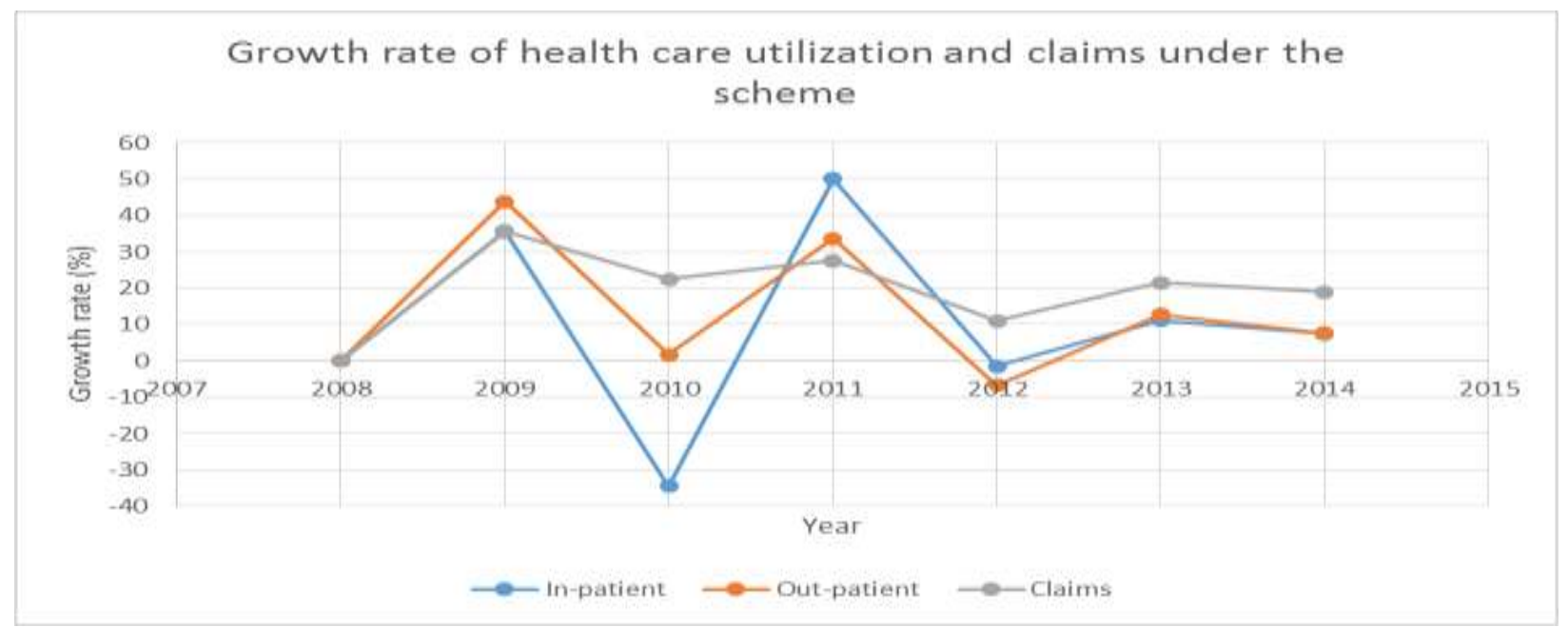

Figure 3:- Growth rate of utilization and claims under GNHIS.

\section{Growth Rate of Active Membership, Claims, and Premium:-}

The sustenance of an insurance policy largely depends on its membership base and the correspondence contributions (premium) paid by its members. This analogy sits well with the propositions of social capital theory.

Woolcock and Narayan (2000) argue that social capital helps the poor to manage risk and vulnerability ${ }^{[23]}$. The ACT 650 which promulgated NHIS as a risk management policy made it compulsory for all residence in Ghana to Enroll $^{[13]}$. However, enrollment under the scheme has not been steady as expected. While there seems to be a substantial coverage nationwide, the active membership under the scheme shows an undulating or slightly declining trend over the years. From 2009 to 2010, the growth of active membership dwindled by 78\%, in real figures the scheme recorded a decline in active membership from 14.51178 million in 2009 to 8.163714 million in 2009 . However, membership soared again in the subsequent year probably due to regain of trust in the scheme through political stability. Since then, membership has assumed undulating trend.

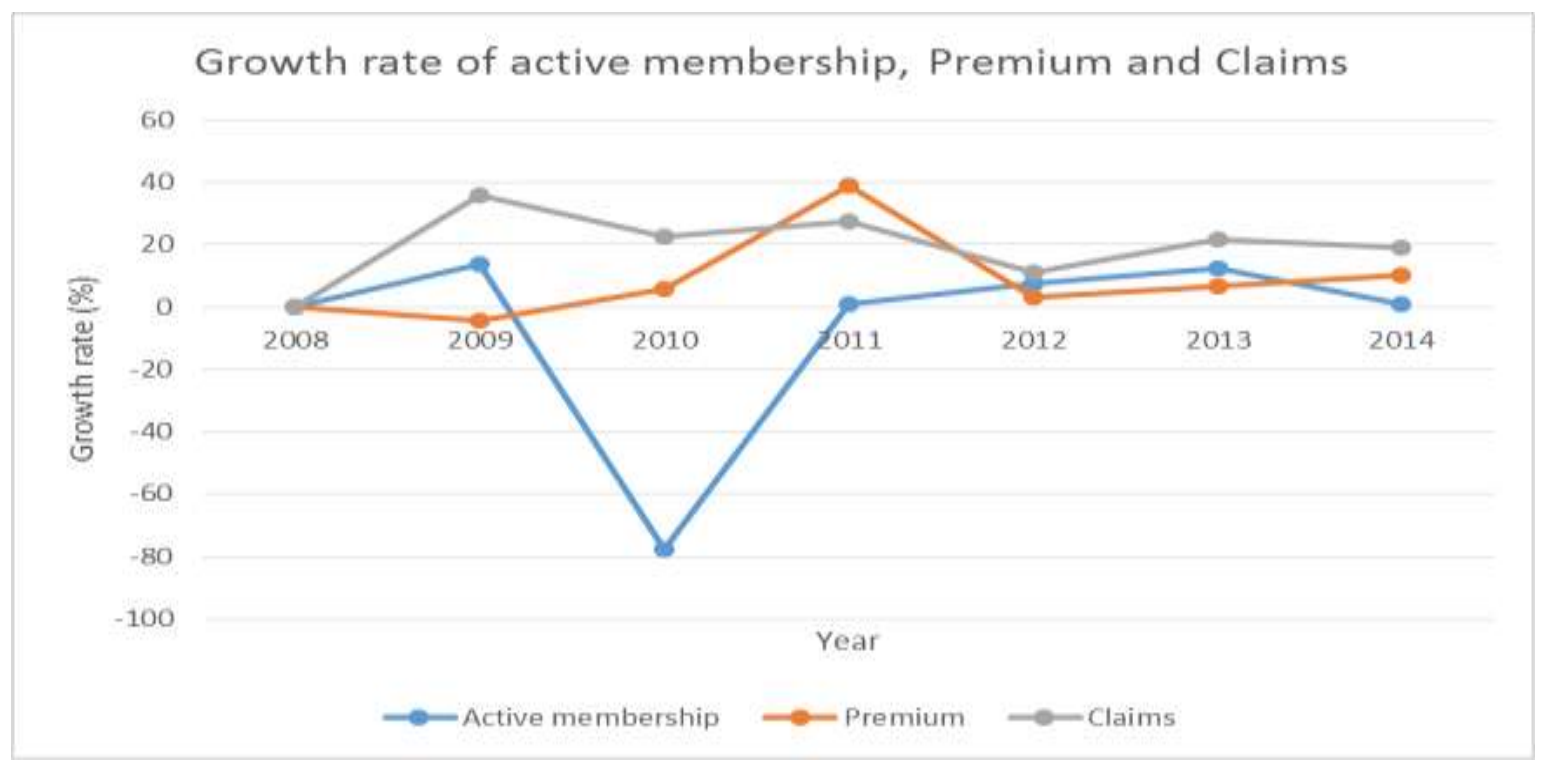

Figure 4:- Growth rate of membership, premiums, and claims. 
From 2008 to 2011, premium recorded positive growth attaining the highest peak in 2011 and started declining sharply in the subsequent years. The rate of growth has decreased from $27.5 \%$ in 2011 to $18.8 \%$ in 2014 . While the growth rate of premium has been declining, claims have been wavering over the years assuming its apex in 2009 and keeps moving up and down. Claims assumed superior growth over premium and active membership from 2012 to 2014. Anang (2011) concluded that the scheme has been roping in more exempted groups since 2010 and this has partly accounted for the trailing of premium behind claims over the years ${ }^{[24]}$. This trend has manifested in the scheme's annual financial reports, recording net operating deficit since 2009.

Income and Expenditure Trends:-

Empirical evidence suggests that financial sustainability of a non-profit organization relies on its capacity to collect revenues in response to a request, to sustain fruitful processes at a steady or increasing rate to produce results and to obtain a surplus (Leon 2001) ${ }^{[15]}$. The author further argues that for non-profit schemes to be financially sustainable there should be extra fund to take advantage of opportunities as well as absorb itself from unforeseen financial burdens that may arise. Leon's argument in her Four Pillars of Financial Sustainability summarized in the mathematical equation below;

Financial Sustainability $=>$ Total Income - Total Cost $=$ Surplus

GNHIS Income \& Expenditure Trends: 2008-2014

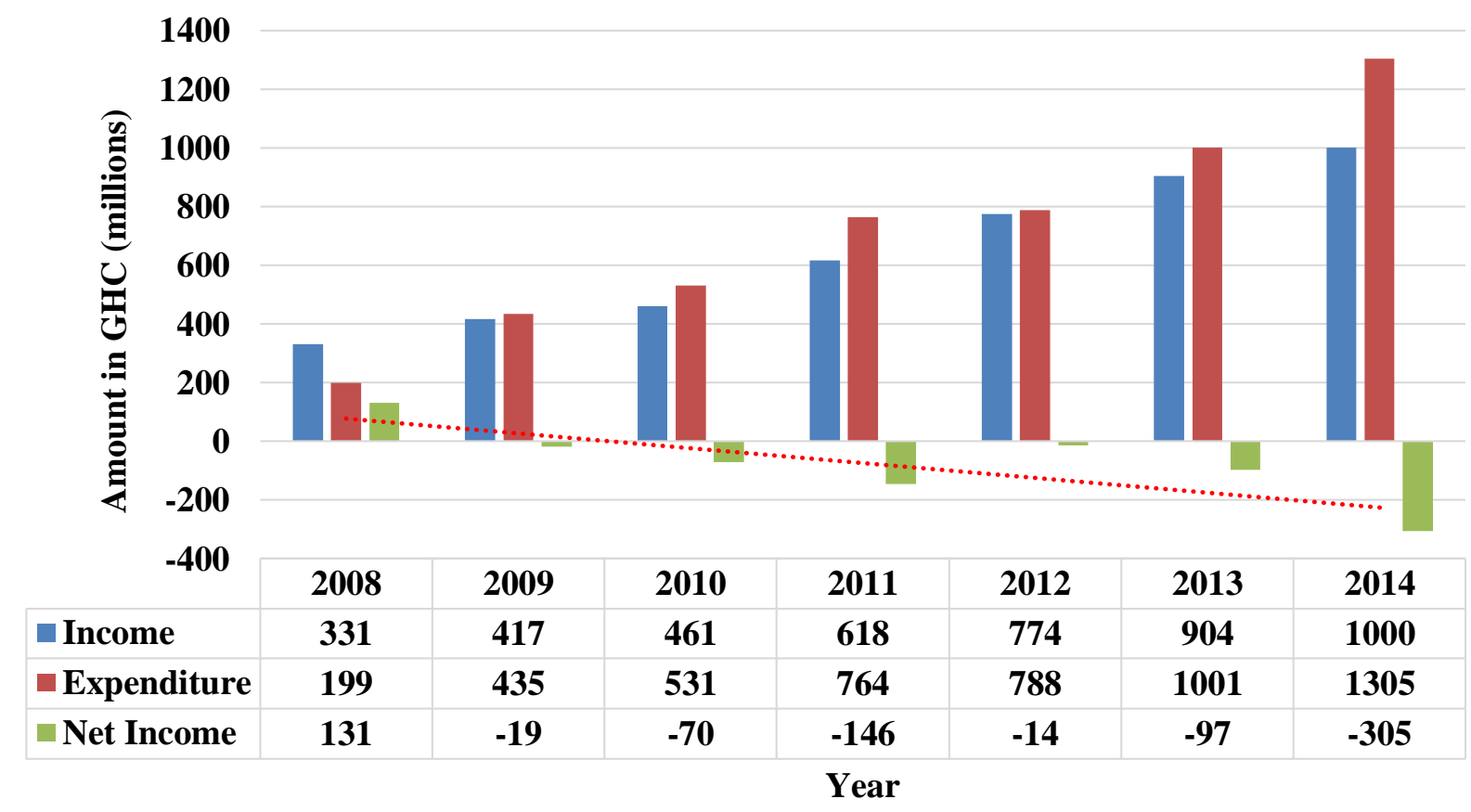

Income Expenditure Net Income $\quad \cdots \cdots \cdots \cdot$..... Linear (Net Income)

Figure 5:- Income and Expenditure trend

Ghana's NHIS has been suffering financial inadequacy in recent years as presented in Figure 5 with a trailing of income behind expenditure. The financial challenges began in May 2008, which marked a departure from the old tariffs using itemized billing with the introduction of the new taxes using DRGs. In both schemes, this resulted in an approximately fourfold increase in the tariffs paid to the providers. It posed a challenge, as schemes were not always adequately resourced to pay providers ${ }^{[14]}$. The scheme has operated on a net deficit since the year 2009 up to the time of this study (2018). With regards to the study's review years, there is a steady increase of deficit recorded. Between 2012 and 2014 for instance, there is a shop up of the operational debt as proposed by Jehu-Appiah's research $^{[14]}$. The study opines that, if no action is taken toward significant additional funding to clear 2014 arrears as well as funding gap for 2015 , the year 2016 will pose an impossible challenge ${ }^{[14]}$. It is undoubtedly clear that 
Ghana's NHIS is in financial distress which needs urgent attention to save the scheme from imminent sustainability threat.

\section{GNHIS Exemption Policy:-}

Welfare theory evolved from the social services state; "the practice of providing needed services to less privileged individuals in society." GNHIS has a policy which exempts specific categories of people from payment of registration fee as well as premium. The import of this exemption policy is to ensure equity and accessibility of health care to all manner of individuals in society.

Table 3:- summary of exemption policy of the GNHIS

\begin{tabular}{|c|c|c|c|c|}
\hline Category & Premium & $\begin{array}{l}\text { Processing } \\
\text { Fee }\end{array}$ & $\begin{array}{l}\text { Waiting } \\
\text { Period }\end{array}$ & $\begin{array}{l}\text { Renewal } \\
\text { Fee }\end{array}$ \\
\hline Informal sector & Yes & Yes & Yes & Yes \\
\hline Under 18years & No & Yes & Yes & Yes \\
\hline 70years and above & No & Yes & Yes & Yes \\
\hline SSNIT contributors & No & Yes & Yes & Yes \\
\hline SSNIT Pensioners & No & Yes & Yes & Yes \\
\hline Indigents/LEAP beneficiaries & No & no & Yes & Yes \\
\hline Pregnant women & No & No & No & No \\
\hline $\begin{array}{lccc}\begin{array}{l}\text { Persons with } \\
(\mathrm{PWD} / \mathrm{PWMD})\end{array} & \text { disability/mental } & \text { disorder } \\
\end{array}$ & No & No & No & No \\
\hline
\end{tabular}

Jehu-Appiah (2014) found out that, out of the total membership of the NHIS in 2014, only $31 \%$ pays a premium. This percentage constitutes the informal sector workers who have subscribed to the scheme. The remaining $69 \%$ comprising children under 18years, adults above 70years, SSNIT contributors and pregnant women are all exempted from payment of premium. Other exempted categories include indigents (absolutely poor), physically challenged persons and mental health patients (see Table $3 \&$ figure 6 for details). While it's a good thing to provide financial protection for the poor and vulnerable in society, the scheme is grappling with serious financial issues to deliver quality services to its clients partly due to the scope of exempted categories. Moreover, government allocations to the scheme have been to be woefully inadequate and thus does not commensurate with utilization cost of the exempted groups[14]. Anang (2011) also found that, the more successful the NHIS regarding coverage, the higher the risk of financial difficulties[24]. To efficiently sustain the exemption policy, and to turn around the financial fortunes of the scheme, government of Ghana must be committed to allocating more funds timeously to the scheme to cater for health care needs of the masses.

\section{GNHIS: Exemption Policy - 2014}

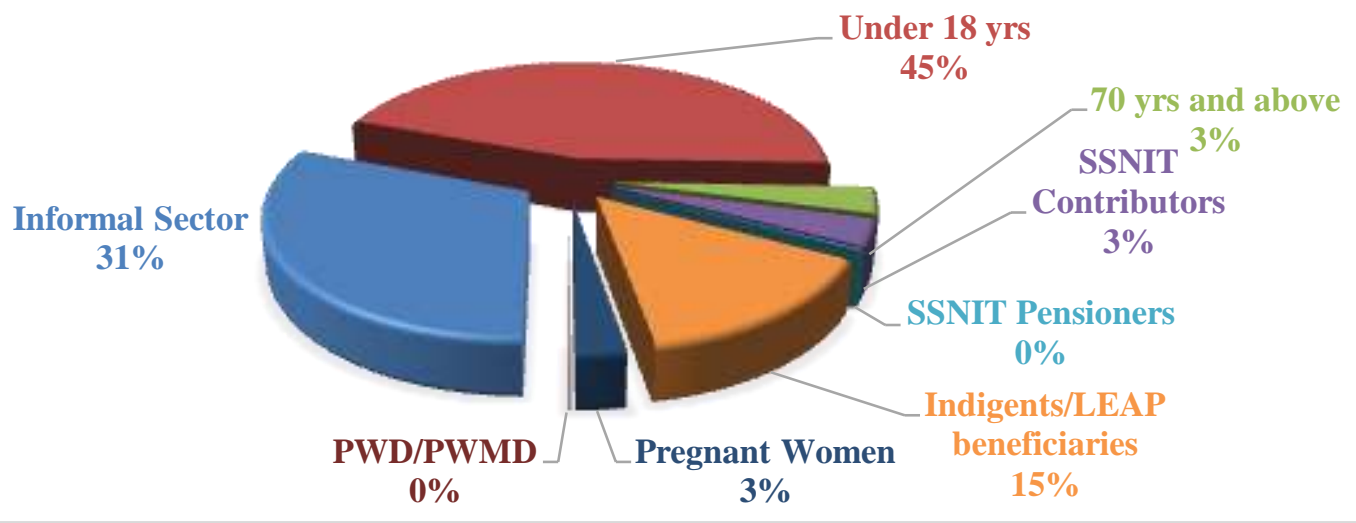

Figure 6:- Exemption Policy under GNHIS.

Quantitative Analysis of Claims, Investments and Financial Sustainability of the GNHIS:-

The study used eight (8) year data period (2008 - 2014), and there were a total of 7 observations (N) as shown in Table 4 
Table 4:- Pearson Correlation Model

\begin{tabular}{|c|c|c|c|c|c|c|c|c|}
\hline \multirow[t]{2}{*}{ Independent Variable } & \multirow[t]{2}{*}{$\mathbf{N}$} & \multirow[t]{2}{*}{ Mean } & \multirow{2}{*}{$\begin{array}{l}\text { Standard } \\
\text { Deviation }\end{array}$} & \multirow[t]{2}{*}{ Min } & \multirow[t]{2}{*}{ Max } & \multicolumn{3}{|c|}{ Pearson Correlations } \\
\hline & & & & & & ROA & INV & $\mathbf{C}$ \\
\hline Return on Assets(ROA) & 7 & 0.1926392 & 0.1557959 & 0.0246044 & 0.464251 & 1 & & \\
\hline Investment (INV) & 7 & 41.41571 & 19.95399 & 16 & 75.64 & -0.6776 & 1 & \\
\hline Claims $(\mathrm{C})$ & 7 & 546.1443 & 270.9377 & 198.11 & 968.48 & 0.5034 & -0.6263 & 1 \\
\hline
\end{tabular}

Test of stationarity, multicollinearity, and heteroskedasticity:-

The Augmented Dickey-Fuller (ADF) test of unit roots was used to assess the stationarity of the data series. Return on Assets (ROA) and Investment (lnINV) were stationary at the level, but Claims (lnC) fixed at first difference. Moreover, to ensure that the results are consistent with classical linear regression assumption, multicollinearity, heteroskedasticity, and autocorrelation (up to order one) were tested. The Variance Inflation Factor (VIF) was used to check for multicollinearity (see Table 5); Breusch-Pagan (BPG) test to check for the appearance of heteroskedasticity; and the Breusch (BG) Test to check for the first-order autocorrelation.

Table 5:- Stationarity Output of (ADF) Test

\begin{tabular}{|l|l|l|}
\hline Variable & VIF & $1 /$ VIF \\
\hline $\operatorname{lnC}$ & 1.10 & 0.906775 \\
\hline $\operatorname{lnINV}$ & 1.10 & 0.906775 \\
\hline Mean VIF & $\mathbf{1 . 1 0}$ & \\
\hline
\end{tabular}

Note: VIF $(j)=1 /(1-R(j) \wedge 2)$, where $R(j)$ is the multiple correlation coefficient between variable $j$ and the other independent variables. Minimum possible value $=1.0$. Values $>10.0$ may indicate a multicollinearity problem;

The results from Table 5 show that none of the variables has a VIF of 10 or more and hence there is no problem of multicollinearity. Again, the Breusch-Pagan/ Cook-Weisberg test for heteroskedasticity showed a Chi2 (2) = 1.46 with p-value $=.2271$. Since the p-value is statistically higher than the level of significance used in the study $(\alpha=0.05)$, the study cannot reject the null hypothesis that 'Heteroskedasticity not present.' Hence, there is no problem of heteroskedasticity. The Breusch-Godfrey LM test for autocorrelation, AR (1) showed a test statistic a Chi2 = 0.672 with $\mathrm{p}$-value $=.4124$. Again, since the $\mathrm{p}$-value is statistically higher than the level of significance used in the study $(\alpha=0.05)$, the study cannot reject the null hypothesis (Ho: no serial correlation). Thus, there is no problem of Autocorrelation.

\section{Regression Results and Discussion:-}

The regression output is in table 5-5. The results show a statistically significant negative relationship between ROA and $\operatorname{lnINV}(\beta=-0.1700964, \mathrm{p}=0.049)$. The results imply that one unit (or percentage) point increase (or decrease) in the scheme's investments (and consequently on returns on investments) causes the scheme's ROA to decrease (or increase) by approximately 0.17 units (percentage) points, all things being constant. Practically, in the short run, the more GNHIS diverts funds into investments, the more likely it is to face financial stress, especially in redeeming its financial obligations to service providers and other administrative expenditure. Even though, the available evidence in the literature advocate for diversification of funds by non-profit schemes to ensure financial sustainability (Leone $2011)^{[15]}$, in the case of NHIS funds must not be overly invested at the expense of mandatory financial obligation. Since most of these investments are long-term, scheme managers must be cautious not to cash-trap the scheme before the invested capital yields returns. It is therefore essential that a right balance between investment decisions and availability of adequate funds to deliver core mandate of organizations be maintained for the financial health of the scheme.

Similarly, Table 6 shows a statistically significant negative relationship between ROA and $\operatorname{lnC}(\beta=-0.2278903$, $\mathrm{p}=0.036$ ). It means that one unit (or percentage) point increase (or decrease) in the claims by service providers on the scheme causes the scheme's ROA to decrease (or increase) by approximately 0.23 units (percentage) points, ceteris paribus. This inverse relationship between claims and ROA indicates that, as claims payment under the scheme increase, funds dissipates rapidly leaving the scheme to financial turmoil. Conversely, the scheme becomes more profitable and sustainable when the growth rate of claims checked with cost containment measures.

Table 6:- Summary of Regression output 


\begin{tabular}{|c|c|c|c|c|c|}
\hline $\begin{array}{l}\text { Dependent } \\
\text { Variables }\end{array}$ & $\begin{array}{l}\text { Independent } \\
\text { Variables }\end{array}$ & Coefficient ( $\beta$ ) & Std. Err. & t-ratio & $p>t$ \\
\hline \multirow[t]{3}{*}{ ROA } & $\operatorname{lnINV}$ & -0.1700964 & .0531377 & -3.20 & $0.049 * *$ \\
\hline & $\ln C$ & -0.2278903 & .0626551 & -3.64 & $0.036^{* *}$ \\
\hline & cons & 0.8498613 & .1907452 & 4.46 & 0.021 \\
\hline
\end{tabular}

$* * *, * *$ and $*$ denote significance at $1 \%, 5 \% \& 10 \%$ respectively

Again, the regression result in Table 6 depicts an adjusted R-squared of 0.8639. Thus jointly, investment (INV) and claims $(\mathrm{C})$ explain more than 86 percent of the variation in schemes profitability (surplus or deficit generation). The test of overall significance also showed a test statistic value of 16.87 with a p-value $=.021(<0.05)$. It means that the two independent variables jointly have a statistically significant effect on the GNHIS's surplus or deficit generation. The overall effect is significant at 5 percent level.

\section{Conclusion:-}

Although some healthcare insurance schemes are springing up rapidly, there are only a few schemes in existence in Africa today, and these provide essential health care coverage to less than ten percent (10\%) of the developing world's population. The objective of this study can be sum up as determining the funding adequacy of Ghana's National Health Insurance scheme, the relationship between funding returns on investment and claims payment and financial sustainability strategies of the scheme. Through the review of previous literature in the field of financial sustainability of health insurance schemes and also adopting time series approach to regress data on the financial report of GNHIS between 2008 and 2014, the study concludes that GNHIS needs immediate policy diagnostics and operational restructuring to avert the financial challenges bedeviling the scheme currently. The scheme stands a risk of collapsing in the immediate future if the financial quagmire evidenced in this study not addressed immediately.

\section{Recommendations:-}

For the scheme to be sustained and the purpose of its implementation achieved, the following measures need to be adopted to salvage the scheme from collapsing.

Stakeholders could increase the income of the scheme by having the courage and willpower to:

* Increase the subscription premium currently charged

* Increase the government subsidy paid to the scheme to commensurate with the expanding exempted groups subscribed to the scheme.

* Institute cost containment measures such as co-payments, proper accounting and evaluation systems to audit claims submitted by providers.

* Taxes could be added to items such as cigarette and alcoholic drinks which have an indirect adverse effect on the health of customers while rising income to the scheme.

* Impose a tax on companies whose operations affect/pollute the environment which has adverse health consequences for citizens to support the scheme.

Strategically, the health insurance authority can embark on health promotional campaigns to reduce the disease burden of the scheme. 


\section{References:-}

1. UNESCO, "Population Education in Health. Regional Institute for Education in Asia and Oceania," Bangkok., 1980 .

2. UNICEF, "Health Insurance in low-income countries, Briefing Paper, 2008.," 2008.

3. Appiah-Denkyira E, Preker A, "Reaching the poor in Ghana with national health insurance-an experience from the districts of the Eastern region of Ghana," Extending Soc. Prot. Heal. Dev. Countries' Exp. Lessons Learn. Recomm., pp. 1-225, 2007.

4. WHO, "World Health Report," 2002.

5. L. Liang and J. C. Langenbrunner, "The long march to universal coverage: lessons from China," pp. 1-58, 2013.

6. G. Abekah-Nkrumah, T. Dinklo, and J. Abor, "Financing the health sector in Ghana: A review of the budgetary process," Eur. J. Econ. Finance. Adm. Sci., vol. 17, no. 17, pp. 45-59, 2009.

7. D. Adesina, "The National Health Insurance Scheme," Nigerian Doctor 10 April, p. 19, 2009.

8. NHIA, "Ghana National Health Insurance Scheme Annual Report 2009," Accra, Ghana, 2010.

9. NHIA, "Ghana National Health Insurance Scheme Annual Report 2010," Accra, Ghana, 2011.

10. NHIA, "Ghana National Health Insurance Scheme Annual Report 2011," Accra, Ghana, 2012.

11. NHIA, "Ghana National Health Insurance Scheme Annual Report 2012," Accra, Ghana, 2013.

12. NHIA, "Ghana National Health Insurance Scheme Annual Report 2013," Accra, Ghana.

13. NHIA, "Ghana National Health Insurance Scheme Annual Report 2014,” Accra, Ghana, 2015.

14. C. Jehu-Appiah, G. Aryeetey, E. Spaan, I. Agyepong, and R. Baltussen, "Efficiency, equity and feasibility of strategies to identify the poor: An application to premium exemptions under National Health Insurance in Ghana," Health Policy (New. York)., vol. 95, no. 2-3, pp. 166-173, 2010.

15. P. León, "Four pillars of financial sustainability," Resour. Success Ser., vol. 2, p. 29, 2001.

16. Kofi Owusu Yeboah1* Moses Kormedoda2, "A Study into the Financial Sustainability of Offinso Mutual Health Insurance Scheme," Res. J. Financ. Account., vol. Vol.5, no. 15, 2014.

17. M. Welman, Kruger, Research methodology, 3rd ed. Capetown; Oxford: Capetown; Oxford: Oxford University Press, 2005., 2005.

18. J. S. Chipman, "Gauss-Markov Theorem," International Encyclopedia of Statistical Science, 2011. [Online]. Available: http://link.springer.com/10.1007/978-3-642-04898-2_270. [Accessed: 25-Oct-2016].

19. T. B. Fomby, "Augmented Dickey-Fuller Unit Root Tests," 2006. [Online]. Available: https://en.wikipedia.org/wiki/Augmented_Dickey-Fuller_test. [Accessed: 25-Oct-2016].

20. R. G. Eccles, I. Ioannou, and G. Serafeim, "The Impact of Corporate Sustainability on Organizational Processes and Performance," Manage. Sci., vol. 60, no. 11, pp. 2835-2857, 2014.

21. "the possibility of Heteroskedasticity," $2010 . \quad$ [Online]. http://www.reed.edu/economics/parker/s12/312/notes/Notes8.pdf. [Accessed: 15-Oct-2016].

22. A. Akpalu, Dr, "10 years of Financial Access to Quality Healthcare. 'Towards Universal Health Coverage: Increasing Enrolment while Ensuring Sustainability.""

23. M. Woolcock and D. Narayan, "Social Capital: Implications for Development Theory, Research, and Policy," Source World Bank Res. Obs., vol. 15, no. 2, pp. 225-249, 2000.

24. R. C. Anang, "on the Sustainability of Ghana National Health Insurance," 2011. 